\title{
Overall Fitness Benefits in Individuals with HIV Participating in a Community- Based Exercise Program
}

\author{
Elizabeth Orozco PT, DPT, Martín G. Rosario* PT, Ph.D., CSFI, ATRIC
}

Physical Therapy Program, Texas Woman's University, Dallas Campus; Texas, United States.

\author{
Article Details \\ Article Type: Research Article \\ Received date: $19^{\text {th }}$ June, 2020 \\ Accepted date: $10^{\text {th }}$ August, 2020 \\ Published date: $13^{\text {th }}$ August, 2020
}

*Corresponding Author: Martín G. Rosario PT, Ph.D., CSFI, ATRIC, Physical Therapy Program, Texas Woman's University, Dallas Campus; 5500 Southwestern Medical Ave. Dallas, TX 75235-7299, United States. E-mail: mrosario1@twu.edu

Citation: Orozco, E., \& Rosario, M.G. (2020). Overall fitness benefits in individuals with HIV participating in a communitybased exercise program. J Rehab Pract Res 1(2):109. https://doi.org/10.33790/jrpr1100109

Copyright: (C2020, This is an open-access article distributed under the terms of the Creative Commons Attribution License 4.0, which permits unrestricted use, distribution, and reproduction in any medium, provided the original author and source are credited.

\begin{abstract}
s
People living with human immunodeficiency virus (HIV) withstand various complications that negatively impact multiple body systems such as cardiovascular and immune systems. Exercise therapy has been found to sustain and even improve the health of people living with HIV. However, the advantages of a community-based exercise program targeting Hispanic-Latinos with HIV are yet to be studied.

Purpose: The study aimed to identify the effects of a communitybased exercise program on immunity (CD4 count), cardiovascular fitness, and muscular fitness in Hispanic-Latino individuals living with HIV.
\end{abstract}

Subjects and Methods: Twenty- five adults with HIV (ages 55.6 \pm 9.6 years) participated in this study. The current inquiry was a retrospective cohort study that used data collected from individuals who participated in a community organization, known as La Perla de Gran Precio, in San Juan, Puerto Rico. A certified personal trainer performed all exercise testing. Cardiovascular fitness was assessed using the Ross Submaximal Treadmill Test. Strength was measured by determining the 1-repetition maximum (1-RM) for bench press and leg press. Muscular endurance was assessed by measuring the maximum number of push-ups and sit-ups that could be completed in 1 minute. Flexibility was tested using the Sit and Reach Test. Immune function (CD4 count and viral load) was measured by asking participants to bring a copy of their most recent lab results to each fitness evaluation. The same assessment was administered three more times to track participants' progress over a year.

Results: There was a significant difference in CD4 counts over the four evaluations, $F(3,69)=6.947, \mathrm{p}<.001$. However, results from Freidman's ANOVA also revealed a significant reduction in heart rate $(\mathrm{p}=.005)$ during the submaximal exercise test.

Conclusion: Participation in community-based exercise programs can help improve immune function and cardiovascular fitness in people with HIV. Therefore, people with HIV should engage in regular exercise and be introduced to community/recreational programs.

\section{Introduction}

Human Immunodeficiency Virus (HIV) affects about 37.9 million people worldwide [1, 2]. HIV attacks the immune system by destroying CD4 cells. After acquiring the virus, if left untreated, the amount of CD4 cells will decrease, and the body will become more vulnerable to opportunistic infections, which can lead to acquired immunodeficiency syndrome (AIDS). As the virus progresses, it continues to multiply, increasing the viral load or copies of the virus in the host's system [2]. Advances in antiretroviral therapy (ART) have increased the life expectancy of persons living with HIV; however, living longer has resulted in adverse consequences from the medication and other chronic health conditions associated with the sequela of the disease $[2,3]$. Consequently, people living with HIV develop various physical impairments, activity limitations, and psychological issues. Exercise has been used to improve and sustain the health of people living with HIV $[4,5]$. Evidence suggests that a combination of aerobic and resistance training improves cardiorespiratory fitness, muscle strength, body composition, and quality of life in this population [3-5]. In fact, many studies have examined the effects of exercise when performed in a clinical setting, but O'Brien and colleagues suggested that the benefits of a community based exercise program should be considered in this population $[4,5]$. Community-based exercise programs can be used to increase physical activity participation in people living with HIV $[6,7]$ However, it is unclear whether exercise improves immune function in this population $[4,5,8-10]$. Therefore, the purpose of this study was to identify the effects of a community-based exercise program on immunity, cardiovascular fitness, and muscular fitness in Hispanic-Latino individuals living with HIV. It was hypothesized that year-long participation in a community fitness center would improve cardiovascular fitness, muscular fitness, and immune function in Hispanic-Latinos living with HIV.

\section{Methods}

A retrospective cohort study was conducted on data collected at La Perla de Gran Precio (LDPG) in San Juan, Puerto Rico, a nonprofit organization that serves people living with HIV. This study followed all the established privacy requirements and was approved by the LDPG Institutional Board. As part of the requirements of the La Perla de Gran Precio, the participants took part in a communitybased exercise program.

There are various requirements that must be met in order to participate in clinic services, including a signed participation form from their primary doctor, which ensures participants are safe to partake in the LDGP activities. Secondly, participants underwent an initial evaluation by a licensed physical therapist employed by LDGP. The purpose of the evaluation was to review the participant's medical history for any comorbidities, identify physical impairments, 
establish a baseline for physical fitness level, and approve the fitness evaluation with or without modifications. If the participant was deemed appropriate and able to participate in an exercise program, then the participant completed a fitness evaluation that was conducted by a certified personal trainer. The physical fitness test was divided into the following three components:

Cardiovascular fitness test: The Ross Submaximal Treadmill Test was used to assess cardiovascular fitness. To begin the test, each participant's resting heart rate and blood pressure were obtained to establish baseline values. A heart rate monitor was used to record the activity of the heart. The speed of the treadmill began at $2.0 \mathrm{mph}$, and after 4 minutes was increased to $3.4 \mathrm{mph}$ for the remainder of the test. The incline started at $0 \%$ but was increased by $3 \%$ after the first 6 minutes and then every 3 minutes after that. If the participants were physically able, the test would continue for a total of six stages and 21 minutes. Heart rate and time completed were recorded at the termination of the test.

Muscular fitness tests: Muscle strength and muscle endurance are both components of muscular fitness [11]. Muscular strength is defined as the amount of force that can be exerted by a single muscle or group of muscles [11]. Whereas, muscular endurance is the ability of a muscle group to perform a movement over a period of time repeatedly [11]. In this study, strength was assessed by determining the 1-repetition maximum (1-RM) for bench press and leg press, which are both reliable and valid methods for measuring upper and lower body strength in middle-aged and older adults [1113] Muscular endurance was measured by recording the maximum number of push-ups and sit-ups completed in 1 minute.

Flexibility test: The Sit and Reach Test, a standard measure of hamstring and lumbar extensibility, was used to measure flexibility. The Sit and Reach Test has moderate to low mean criterion validity for determining hamstring flexibility and lumbar extensibility [14]. This test is relatively simple and requires minimal equipment and space to perform; therefore, this test was considered a practical test for the location and size of the sample group.

Immune function: Participants were asked to bring a copy of their most recent lab results to each fitness evaluation to obtain CD4 count and viral load. These values were recorded on the evaluation sheet, and the copy of the lab results was returned to the participant. This same fitness evaluation was administered three more times throughout the year, for a total of four assessments, to track each participant's progress.

Data were collected from participants' records. Approximately 100 records were reviewed for data entireness and acceptance for the established requirements. Records were approved if they met the following inclusion criteria: 1) met all requirements of the LDGP, 2) complete all components of a physical fitness test, 3 ) no history of musculoskeletal injury or surgery in the past six months, 4) CD4 counts greater than 200,5) a community ambulator, 6) actively participating in ART protocol, and 7) cognitively oriented to place, time, and space. The exclusion criteria included the following: 1) pregnant, 2) a history of hospitalization within the last six months, and 3) a reduction in CD4 count of more than 100 points when compared to the two most recent lab results.

Lastly, participants who were currently active in LDGP at the time were identified. There are different explanations individuals stop participating in the LDGP, including hospitalization, psychological hardships, and injury. Most of the time, unless subjects re-established communication with the community center, the reasons for ending the services remained unknown. Therefore, participants included in this study were those who remained active at LDGP for a year with no apparent complications.

\section{Data Analysis}

A series of repeated-measures ANOVA with Bonferroni adjustments were performed to determine whether there was a statistically significant mean difference in CD4 count, cardiovascular fitness (time completed during the submaximal test and cardiac frequency), 1-RM bench press and leg press, the maximum number of pushups and sit-ups that could be executed in 1 minute, and flexibility between evaluations. The assumption of sphericity was met for all variables except for heart rate; however, due to the small sample size and possible violations of normality, a Friendman's ANOVA for each outcome variable was also performed. All statistical analyses were performed using SPSS version 25.

\section{Results}

Data from 25 participants (ages 55.6 9.6 years) were included in this study and the demographic information can be found in table 1. Results depicted in table 2 from a repeated-measures ANOVA revealed there was only a significant difference in CD4 counts over the four evaluations, $F(3,69)=6.947, p<.001$. Pairwise comparisons found a significant increase in CD4 counts between evaluation 1 and $3(\mathrm{p}=.009)$ and evaluation 1 and $4(\mathrm{p}=.027)$. The results highlighted in table 3 from Friedman's ANOVA found a significant reduction in heart rate $(p=.005)$ and a significant increase in CD4 counts $(\mathrm{p}<.001)$. Measurements of strength and muscle endurance (bench press and sit-ups) increased over the four evaluations; however, these improvements were not significant ( $p>0.05)$. Further, the time completed on the submaximal tests increased considerably between examinations 1 and 4 , yet, the improvement was non- significant $(\mathrm{p}>0.05)$.

\begin{tabular}{|c|c|}
\hline \multicolumn{2}{|c|}{} \\
\hline Characteristics \\
\hline Age & $55.6 \pm 9.6$ years \\
\hline Gender & 15 male; 10 female \\
\hline Systolic BP $(\mathrm{mmHg})$ & $126.5 \pm 20.39$ \\
\hline Diastolic BP $(\mathrm{mmHg})$ & $77.3 \pm 12$ \\
\hline CD4 & $851.6 \pm 312.7$ \\
\hline Years of diagnosis & $19 \pm 9.2$ years \\
\hline
\end{tabular}

Table 1: Demographic data of all participants 


\begin{tabular}{|l|l|l|l|l|l|l|}
\hline Variable & Evaluation 1 & Evaluation 2 & Evaluation 3 & Evaluation 4 & F & $\begin{array}{l}\text { P } \\
\text { value }\end{array}$ \\
\hline $\begin{array}{l}\text { Bench press } \\
\mathrm{n}=10\end{array}$ & $100.50+/-33.036$ & $107.50+/-33.932$ & $103.00+/-40.222$ & $\begin{array}{l}107.50+/- \\
35.375\end{array}$ & .447 & .721 \\
\hline $\begin{array}{l}\text { Leg press } \\
\mathrm{n}=7\end{array}$ & $340.71+/-163.004$ & $319.29+/-151.724$ & $\begin{array}{l}347.14+/- \\
199.705\end{array}$ & $\begin{array}{l}253.57+/- \\
113.531\end{array}$ & 1.365 & .285 \\
\hline $\begin{array}{l}\text { Push up } \\
\mathrm{n}=7\end{array}$ & $18.14+/-11.006$ & $21.71+/-9.895$ & $22.57+/-19.303$ & $14.71+/-10.858$ & .653 & .592 \\
\hline $\begin{array}{l}\text { Sit up } \\
\mathrm{n}=9\end{array}$ & $36.00+/-21.436$ & $40.44+/-17.721$ & $42.44+/-15.485$ & $43.67+/-15.676$ & 1.403 & .266 \\
\hline $\begin{array}{l}\text { Flexibility } \\
\mathrm{n}=4\end{array}$ & $7.575+/-5.2525$ & $7.8750+/-5.80768$ & $\begin{array}{l}7.6250+/- \\
5.46771\end{array}$ & $7.375+/-5.0229$ & .093 & .962 \\
\hline $\begin{array}{l}\text { Heart Rate } \\
\begin{array}{l}\text { HR } \\
\mathrm{n}=12\end{array}\end{array}$ & $142.58+/-10.723$ & $142.75+/-10.906$ & $135.83+/-15.497$ & $135.58+/-$ & 3.387 & .057 \\
\hline $\begin{array}{l}\text { CD4 count } \\
\mathrm{n}=24\end{array}$ & $695.003+/-318.582$ & $\begin{array}{l}805.863+/- \\
366.3402\end{array}$ & $\begin{array}{l}932.853+/- \\
408.415\end{array}$ & $\begin{array}{l}945.571+/- \\
433.125\end{array}$ & 6.947 & $<.001$ \\
\hline $\begin{array}{l}\text { Cardio Time } \\
\mathrm{n}=12\end{array}$ & $10: 43+/-3: 21$ & $10: 42+/-2: 45$ & $10: 36+/-1: 35$ & $11: 41+/-2: 20$ & .663 & .581 \\
\hline
\end{tabular}

\begin{tabular}{|c|c|c|}
\hline Variable & $\mathbf{x}^{2}$ & Pvalue \\
\hline $\begin{array}{c}\text { Bench press } \\
n=10\end{array}$ & 1.151 & .765 \\
\hline $\begin{array}{c}\text { Leg press } \\
n=7\end{array}$ & 1.045 & .790 \\
\hline $\begin{array}{c}\text { Push up } \\
n=7\end{array}$ & .652 & .884 \\
\hline $\begin{array}{l}\text { Sit up } \\
\mathrm{n}=9\end{array}$ & 2.477 & .480 \\
\hline $\begin{array}{c}\text { Flexibility } \\
n=4\end{array}$ & .158 & .984 \\
\hline $\begin{array}{l}\text { Heart Rate (HR) } \\
n=12\end{array}$ & 12.657 & .005 \\
\hline $\begin{array}{c}\text { CD4 count } \\
n=24\end{array}$ & 21.504 & $<.001$ \\
\hline $\begin{array}{c}\text { Cardio Time } \\
\mathrm{n}=12\end{array}$ & 2.092 & .553 \\
\hline
\end{tabular}

\section{Discussion}

The current study intended to determine if participation in a community-based exercise program would improve cardiovascular fitness, muscular fitness, and immune function in HispanicLatino people living with HIV. This study showed that yearlong participation in a community-based exercise program could improve immune function and cardiorespiratory fitness, as evident by a considerable increase in CD4 count and reduction in heart rate response $(p<0.05)$ on the Ross Submaximal Treadmill Test. Withal, progress in muscular fitness varied amongst the evaluations and did not indicate a statistically significant difference. Therefore, considering those mentioned above, the established hypothesis was partially accepted.

\section{Cardiovascular Fitness}

This study found a statistically significant reduction in heart rate during the submaximal exercise test. In addition, there was an increase in time completed on the Ross Submaximal Treadmill
Test; however, the finding was non-significant. Similar discoveries were ascertained in a study by Hand et al. in 2008, where subjects with HIV who participated in a 6-week integrated exercise program at moderate intensity revealed a significant increase in $\mathrm{VO} 2$ max and time to complete the submaximal test in addition to the considerable reduction in submaximal heart rate [15]. A reduction in heart rate response achieved during submaximal exercise is commonly known as the bradycardia effect. The bradycardia effect is a positive response to cardiovascular training in healthy individuals and has been documented in those living with HIV $[3,11]$. Since cardiac dysfunction is prevalent in people living with HIV and can lead to a reduction in functional aerobic capacity, there is ample research supporting the benefits of regular involvement in aerobic exercise to reduce cardiovascular impairments in this population $[4,15]$. In fact, a systematic review and meta-analysis by O'Brien et al. suggested individuals with HIV should participate in aerobic exercise or a mixture of aerobic and resistance training at least three to five times a week to achieve cardiorespiratory benefits [4]. Although the findings 
from the Ross Submaximal Treadmill Test were non-significant, we inferred the outcomes presented in this study are still representative of a definite advantage of cardiovascular training. Dolan et al. in 2006 found that women with HIV who underwent a 16-week exercise program demonstrated an increase in time during a submaximal exercise test and an increase in distance traveled during a 6-minute walk test.16 We deduced that the p-value outcomes above the alpha level of 0.05 in our study were related to the small sample size and the various fitness levels of the participants. One of the limitations of this study is related to the reduced attrition rate of the participants of LPDG. This study collected data from participants' records. Hence, we did not design the protocols mentioned in this report, making it troublesome to identify completed documents with the four assessment data points.

We recommend developing a longitudinal study in this particular Hispanic-Latino group to better comprehend the cardiorespiratory benefits of engaging in a year-long exercise program.

\section{Muscular Fitness}

In this study, improvements were seen in upper and lower body strength and muscular endurance over the year-long program. While these findings were non-significant from a statistical perspective, they are invariant with past evidence that suggests progressive resistive training can enhance muscular fitness in people living with HIV [5]. Related discoveries were found in a study where elderly individuals with HIV underwent a combined exercise program (aerobic and resistance training) twice a week for a year. These participants demonstrated significant improvement in the strength of both upper and lower body muscle groups [17]. Furthermore, Garcia et al. in 2014 established that people living with HIV who partook in a 20week integrated exercise program $3 \mathrm{x} /$ week showed improvements in muscle endurance of the abdominal muscles and muscle strength of the arms and legs [18]. Repeatedly, resistive training has been shown to improve strength, muscle mass, body composition, and weight in people living with HIV [5]. Therefore, it has been proposed that resistance training should be performed at moderate intensity (60$80 \%, 1-\mathrm{RM})$ at least three times a week in this population $[5,19]$. While our study did not produce significant findings, we acknowledge this was related to the possible onset of new injuries, reduction in the overall health of the individual, or potential gaps in exercise training.

\section{Flexibility}

Our findings showed a non-significant difference in flexibility outcomes as measured by the Sit and Reach Test. However, we surmise this outcome was due to the small sample size $(n=4)$ that completed flexibility testing across all four evaluations and possibly non-compliance with the exercise program. Flexibility outcomes have been measured in other studies and demonstrated a more favorable result. For instance, a systematic review by Voigt and colleagues, found that studies that employed a combination of supervised aerobic and progressive resistive training indicated significant improvements in flexibility [20].

Further, specific flexibility routines have been used in some studies and have considerably improved outcomes on the Sit and Reach Test [21]. In addition, significant flexibility outcomes have even been found following participation in regular aerobic exercise and tai chi [22]. Presently, there are no particular recommendations for flexibility exercises in this population; however, the American College of Sports Medicine (ACSM) has recommended that people living with HIV should follow the flexibility recommendations made for healthy adults. These ACSM guidelines include performing flexibility exercises of major muscle groups at least 2-3 days/week with daily performance being most effective [11].

\section{Immune Function}

The findings of this study highlight a significant improvement in CD4 count over the year-long intervention, indicating an increase in immune function. It has been known that one of the long term benefits of exercise is the reduction of immunosenescence and a boost in immune function, specifically in the production of T-lymphocytes, which consist of CD4 and CD8 cells [23]. Various studies have ascertained improvements in immune function in this population with long term interventions [24-26]. For instance, a study by Yar'zever et al., found that individuals who underwent a 12week cycle ergometer training demonstrated a significant increase in CD4 in addition to a reduction in viral load [26]. While our study did not compare viral load, it has been shown as CD4 count increases, and the viral load should decrease in this population. Souza et al., found that people with HIV that joined in a year-long resistance training program, like this study, had a significant increase in CD4 counts and CD4/CD8 ratio [17]. Similarly, multiple studies have found that a combination of aerobic and resistance training has been shown to improve CD4 and that habitual physical activity is positively correlated with CD4 counts [9, 27-29]. Therefore, regular exercise should be encouraged in this population to help improve immune function. Future studies should also collect information such as the occurrence of hospitalization, an emergency visit to the doctor, sick leave, and anything associated with negatively impacting the immune system during the exercise intervention period to discern how the immune system is adapting to the exercises program.

\section{Conclusion}

This study aimed to examine the effects of a year-long communitybased exercise program in people living with HIV. To our knowledge, this was the first study where the physiological effects of a yearlong community-based exercise program were assessed. Despite the small sample size, the results support existing literature in that chronic exercise training can improve cardiovascular fitness, muscular fitness, and immune function in people living with HIV [3-5, 8-10, 15-20, 24-29]. Therefore, to lessen the effects of the HIV impact on several systems, this study suggests that people living with HIV should be encouraged to participate in regular exercise. More research is needed to better determine the psychological benefits of a community-based exercise program regarding compliance and improvement in physical function in people living with HIV.

Conflicts of interest/Competing interests: Authors report no conflict or competing interest.

\section{References}

1. Basic Statistics. Center of Disease Control. (2020).

2. About HIV/AIDS. Center of Disease Control. (2020).

3. Jaggers, J.R., \& Hand, G.A.(2014). Health Benefits of Exercise for People Living With HIV: A Review of the Literature. Am J Lifestyle Med. 10(3):184-192. doi:10.1177/1559827614538750.

4. O'Brien, K.K., Tynan, A.M., Nixon, S.A., Glazier, R.H. (2016). Effectiveness of aerobic exercise for adults living with HIV: systematic review and meta-analysis using the Cochrane Collaboration protocol. BMC Infect Dis. 16:182. doi:10.1186/ s12879-016-1478.

5. O'Brien, K.K., Tynan, A.M., Nixon, S.A., Glazier, R.H. (2017). Effectiveness of Progressive Resistive Exercise (PRE) in the context of HIV: systematic review and meta-analysis using the Cochrane Collaboration protocol. BMC Infect Dis. 17(1):268. doi:10.1186/s12879-017-2342-8.

6. Montgomery, C.A., Henning, K.J., Kantarzhi, S.R., Kideckel, T.B., Yang, C.F., \& O'Brien, K.K. (2017). Experiences participating in a community-based exercise programme from the perspective of people living with HIV: a qualitative study. BMJ Open. 7(4):e015861.doi:10.1136/bmjopen-2017-015861.

7. Li, A., McCabe, T., Silverstein, E., et al. (2017). CommunityBased Exercise in the Context of HIV: Factors to Consider when Developing and Implementing Community-Based Exercise Programs for People Living with HIV. J Int Assoc Provid AIDS Care. 2017;16(3):267-275. doi:10.1177/2325957416686836. 
1. Bopp, C.M., Phillips, K.D., Fulk, L.J., Dudgeon, W.D., Sowell, R., \& Hand, G.A. (2004). Physical activity and immunity in HIV-infected individuals. AIDS Care. 2004;16(3):387-393. do i: $10.1080 / 09540120410001665385$.

2. Dianatinasab, M., Fararouei, M., Padehban, V., et al. (2018). The effect of a 12-week combinational exercise program on CD4 count and mental health among HIV infected women: A randomized control trial. J Exerc Sci Fit. 16(1):21-25. doi: 10.1016/j.jesf.2018.02.001.

3. Hand, G.A., Lyerly, G.W., Jaggers, J.R., Dudgeon, W.D. (2009). Impact of Aerobic and Resistance Exercise on the Health of HIV-Infected Persons. Am J Lifestyle Med. 3(6):489-499.

4. Pescatello, L.S. (2014). ACSM's guidelines for exercise testing and prescription. 9th ed. Philadelphia, PA: Wolters Kluwer/ Lippincott Williams \& Wilkins Health;

5. Levinger, I., Goodman, C., Hare, D. L., Jerums, G., Toia, D., \& Selig, S. (2009). The reliability of the 1RM strength test for untrained middle-aged individuals. Journal of science and medicine in sport. 12(2), 310-316. doi: 10.1016/j. jsams.2007.10.007.

6. Phillips, W. T., Batterham, A. M., Valenzuela, J. E., \& Burkett, L. N. (2004). Reliability of maximal strength testing in older adults. Archives of physical medicine and rehabilitation. 85(2), 329-334. doi:10.1016/j.apmr.2003.05.010.

7. Mayorga-Vega D, Merino-Marban R, Viciana J. (2014). Criterion-Related Validity of Sit-and-Reach Tests for Estimating Hamstring and Lumbar Extensibility: a Meta-Analysis. J Sports Sci Med. 13(1):1-14.

8. Hand, G.A., Phillips, K.D., Dudgeon, W.D., Lyerly, G.W., Durstine, J.L., \& Burgess, S.E. (2008). Moderate intensity exercise training reverses functional aerobic impairment in HIV-infected individuals. AIDS Care. 20(9):1066-1074. doi:10.1080/09540120701796900.

9. Dolan, S.E., Frontera, W., Librizzi, J., et al. (2006). Effects of a supervised home-based aerobic and progressive resistance training regimen in women infected with human immunodeficiency virus: a randomized trial. Arch Intern Med. 166(11):1225-1231. doi:10.1001/archinte.166.11.1225.

10. Souza, P.M., Jacob-Filho, W., Santarém, J.M., Silva, A.R., Li, H.Y., Burattini, M.N. (2008). Progressive resistance training in elderly HIV-positive patients: does it work?. Clinics (Sao Paulo). 63(5):619-624. doi:10.1590/s1807-59322008000500009.

11. Garcia, A., Fraga, G.A., Vieira, R.C Jr., et al. (2014). Effects of combined exercise training on immunological, physical and biochemical parameters in individuals with HIV/AIDS. J Sports Sci. 32(8):785-792. doi:10.1080/02640414.2013.858177.

12. Gomes-Neto, M., Conceição, C.S., Oliveira, Carvalho V., Brites, C. (2013). A systematic review of the effects of different types of therapeutic exercise on physiologic and functional measurements in patients with HIV/AIDS. Clinics (Sao Paulo). 68(8):1157-1167. doi:10.6061/clinics/2013(08)16.

13. Voigt, N., Cho, H., \& Schnall, R. (2018). Supervised Physical Activity and Improved Functional Capacity among Adults Living with HIV: A Systematic Review. J Assoc Nurses AIDS Care. 29(5):667-680. doi:10.1016/j.jana.2018.05.001.

14. Farinatti, P.T., Borges, J.P., Gomes, R.D., Lima, D., Fleck, S.J. (2010). Effects of a supervised exercise program on the physical fitness and immunological function of HIV-infected patients. J Sports Med Phys Fitness. 50(4):511-518.

15. Galantino, M.L., Shepard, K., Krafft, L., et al. (2005). The effect of group aerobic exercise and t'ai chi on functional outcomes and quality of life for persons living with acquired immunodeficiency syndrome. J Altern Complement Med. 11(6):1085-1092. doi:10.1089/acm.2005.11.1085.
11. Sellami, M., Gasmi, M., Denham, J., et al. (2018). Effects of Acute and Chronic Exercise on Immunological Parameters in the Elderly Aged: Can Physical Activity Counteract the Effects of Aging?. Front Immunol. 9:2187. doi:10.3389/ fimmu.2018.02187.

12. Poton, R., Polito, M., \& Farinatti, P. (2017). Effects of resistance training in HIV-infected patients: A meta-analysis of randomised controlled trials. J Sports Sci. 35(24):2380-2389. doi:10.1080/0 2640414.2016.1267389.

13. Tiozzo, E. (2011). The Effect of Combined Moderate-Intensity Training on Immune Functioning, Metabolic Variables, and Quality of Life in HIV-infected Individuals Receiving Highly Active Antiretroviral Therapy.

14. Yar'Zever, I. S., Abubakar, U., Toriola et al. (2013). Effects of 12 weeks cycle exercise programme on CD4 count and viral load in HIV sero-positive patients in Kano, Nigeria. J AIDS HIV Res. 5(11), 415-421. doi:10.5897/JAHR2013.0261.

15. Pérez-Moreno, F., Cámara-Sánchez, M., Tremblay, J.F., RieraRubio, V.J., Gil-Paisán, L., Lucia, A. (2007). Benefits of exercise training in Spanish prison inmates. Int J Sports Med. 28(12):1046-1052. doi:10.1055/s-2007-965129.

16. Ogalha, C., Luz, E., Sampaio, E., et al. (2011). A randomized, clinical trial to evaluate the impact of regular physical activity on the quality of life, body morphology and metabolic parameters of patients with AIDS in Salvador, Brazil. J Acquir Immune Defic Syndr. 2011;57 Supp1 3:S179-S185. doi:10.1097/ QAI.0b013e31821e9bca.

17. Kinsey, K., McVeigh, J., \& Chantler, I. (2008). Habitual physical activity levels are positively correlated with CD4 counts in an HIV-positive South African population. Afr J AIDS Res. 7(2):237-242. doi:10.2989/AJAR.2008.7.2.9.526. 